\title{
Abbreviated References and Citation
}

Hegel's works are quoted following the Theorie Werkausgabe, abbreviated as "Hegel Werke", followed by the indication of the volume and page. If the English translation is available, I also give the page number of the translation. If it is not, the translation is mine. In some cases I have modified the extant English translations, opting for more literal versions, and eliminating possible sources of ambiguities. If the changes are major ones, I explain my motivations in the footnotes. In general, I do not use capital letters for the English equivalent of words such as "Begriff”, "Wahrheit", "Idee", words that, in some translations, are written with capital letters ("Notion”, "Truth”, "Idea”). This habit generates an emphasis that is absent in the German text, and could be misleading.

Kant's works are quoted following the Königlich Preußische (später Deutsche) Akademie der Wissenschaften edition (quoted as AA, followed by the indication of volume and page. The Critique of Pure Reason is abbreviated, as usual, as A first edition - and B - second edition, followed by the indication of the page). 
